\title{
Short Fiber Reinforced Composite: a New Alternative for Direct Onlay Restorations
}

\author{
Sufyan Garoushi ${ }^{1,2,}$, Enas Mangoush ${ }^{2}$, Pekka Vallittu $^{2}$ and Lippo Lassila ${ }^{2}$ \\ ${ }^{I}$ Department of Restorative Dentistry \& Periodontology, Institute of Dentistry, Libyan International Medical University, \\ Benghazi, Libya \\ ${ }^{2}$ Department of Biomaterials Science and BioCity Turku Biomaterials Research Program, Institute of Dentistry, Univer- \\ sity of Turku, Turku, Finland
}

\begin{abstract}
Objectives: To determine the static load-bearing capacity of direct composite onlay restorations made of novel filling composite resin system which combines short fiber-reinforced composite resin (FC) and conventional particulate filler composite resin (PFC).

Methods: Three groups of onlay restorations were fabricated $(n=8 /$ group); Group A: made from conventional particulate filler composite resin (Z250, 3M-ESPE, USA, control), Group B: made from short fiber-reinforced composite resin (EverX posterior, StickTeck Ltd, member of GC group, Turku, Finland) as substructure with $1 \mathrm{~mm}$ surface layer of PFC, Group C: made from FC composite resin. The specimens were incrementally polymerized with a hand-light curing unit for $80 \mathrm{~s}$ before they were statically loaded with two different sizes $(3 \& 6 \mathrm{~mm})$ of steel ball until fracture. Failure modes were visually examined. Data were analyzed using ANOVA $(\mathrm{p}=0.05)$.

Results: ANOVA revealed that onlay restorations made from FC composite resin had statistically significantly higher load-bearing capacity $(1733 \mathrm{~N})(\mathrm{p}<0.05)$ than the control PFC composite resin $(1081 \mathrm{~N})$. Onlays made of FC composite resin with a surface layer of PFC gave force values of $1405 \mathrm{~N}$ which was statistically higher than control group ( $\mathrm{p}<$ $0.05)$. No statistically significant difference was found in the load-bearing capacity between groups loaded by different ball sizes
\end{abstract}

Significance: Onlay restorations combining base of short fiber reinforced composite resin as substructure and surface layer of conventional composite resin displayed promising performance in high load bearing areas.

Keywords: Short fiber composite, onlay restoration, load bearing capacity.

\section{INTRODUCTION}

A variety of techniques are currently available to restore teeth with moderate coronal defects in the posterior region and the selection of the appropriate modality is dependent on the evaluation of and compliance with numerous criteria. Routine use of metal ceramic crowns instead of gold alloy partial crowns and onlay restorations enforces the removal of healthy enamel and dentin. Adhesively cemented ceramic onlays have been used as an alternative in order to minimize the removal of tooth structure. The greatest success using ceramic onlays was previously limited to anterior teeth with porcelain veneers [1-3]. This was not surprising, as their fracture resistance and abrasiveness were clearly inferior to that of gold alloys. However, after extensive material improvements, ceramic restorations are accepted for restoring posterior teeth with extended lesion today [4]. Despite their

*Address correspondence to this author at the Department of Restorative Dentistry \& Periodontology, Institute of Dentistry, Libyan International Medical University, Benghazi, Libya; Tel: 00218 3967435;

Fax: +358 2333 8390; E-mail: sufgar@utu.fi less than esthetic appearance, the physical properties of gold alloys have created a standard that has been difficult to match; for example, toughness and a high compressive loadbearing capacity $[1,5]$. Particulate filler composite resin (PFC), at one time considered only as a treatment option for anterior teeth, has steadily been found to have wider applications. With the improvements in the mechanical properties of PFCs, their use has been widened not only to the posterior intra-coronal area, but also to extra-coronal restorations, and even complete crowns and fixed partial dentures [6]. Many studies have been undertaken to investigate the filler phases, resin compositions, and curing conditions to improve the mechanical properties of PFC $[1,7,8]$. However, further significant improvements are needed in order to extend the use of PFC to high stress-bearing applications such as direct posterior restorations involving cusps and indirect restoration, inlays and onlays $[1,8]$. In terms of indirect restorations, inlays/onlays have been used for almost 25 years. They were introduced in the hope of overcoming problems associated with the lower degree of conversion related to direct posterior PFCs being placed using conventional incremental techniques. The most common problems that occurred were vari- 

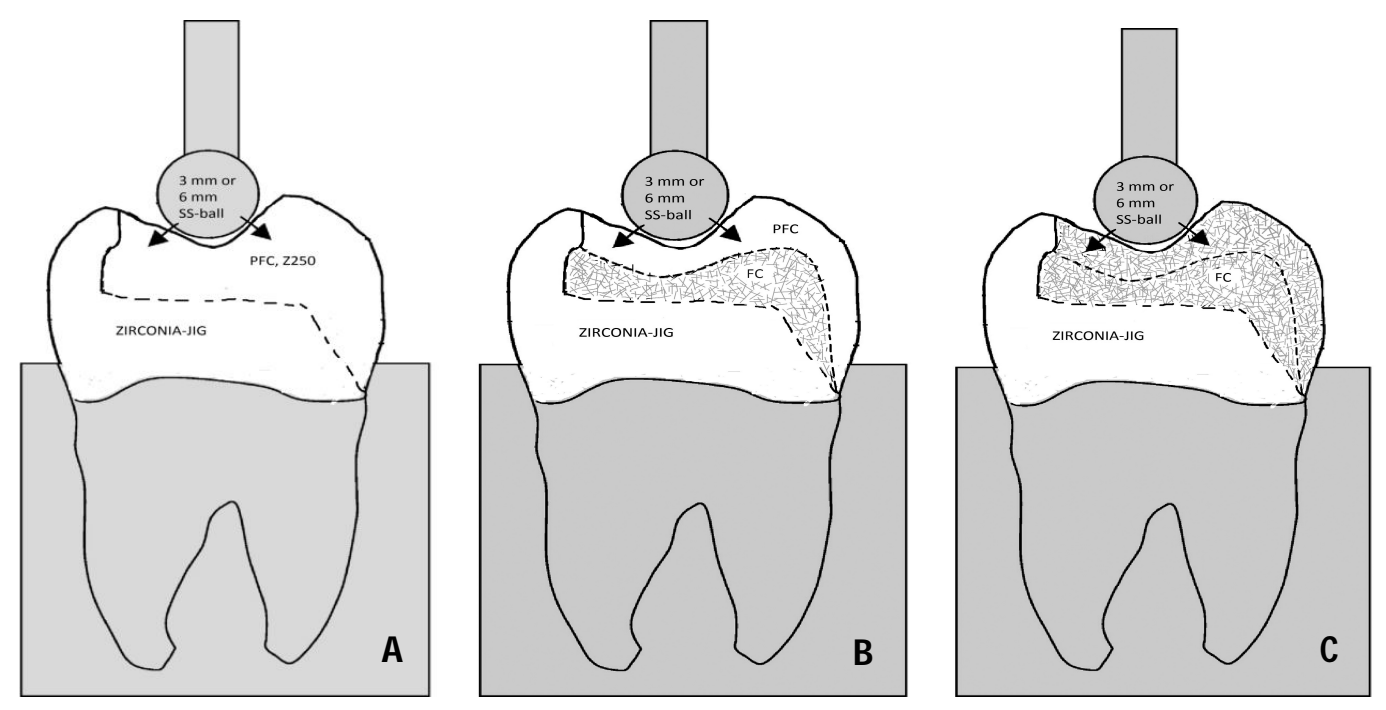

Fig. (1). Schematic drawing of onlay-shaped test specimens and the compressive load test setup. PFC refer to particulate filler composite; FC refer to short/fiber reinforced composite. Group A: only PFC; Group B: PFC+FC; Group C: only FC.

various types of fractures in high stress-bearing areas [1,9]. It was hoped that the use of the indirect technique would improve the load-bearing capacity of the composite by raising the degree of conversion obtained by laboratory postcuring of the restoration. It is reported that extra-oral polymerizations of the composite followed by cementation appear to improve the marginal fit and minimize contraction stress $[1,10]$. The mechanical properties of the composites were also improved by post-cure heat treatment, although such improvements were modest and sometimes not statistically significant $[1,11,12]$. The relatively high brittleness and low load-bearing capacity of current PFCs still hinder their use in large stress-bearing restorations [1, 13-15]. It therefore follows that there is a considerable need for improved mechanical properties, especially load-bearing capacity and wear resistance, whilst still retaining esthetic properties.

Recently, short fiber reinforced composite $\mathrm{FC}$ resin was introduced as a dental restorative composite resin [16-19]. The composite resin is intended to be used in high stress bearing areas especially in molars. The results of the laboratory mechanical tests revealed substantial improvements in the load bearing capacity, the flexural strength and fracture toughness of dental composite resin reinforced with short Eglass fiber fillers in comparison with conventional particulate filler composite resin [16-20]. The short fiber composite resin has also revealed control of the polymerization shrinkage stress by fiber orientation and, thus, marginal micro leakage was reduced compared with conventional particulate filler composite resins [18]. It can be hypothesized that by using a FC composite substructure under PFC, the static load-bearing capacity of the material combination could be improved. Load application over the restoration is one of the factors that could influence the load bearing capacity. Thus, the aim of this study was to determine the static load-bearing capacity with two different loading stresses of direct composite onlay restorations made of novel filling composite resin system which combines short fiber-reinforced composite resin and conventional particulate filler composite resin.

\section{MATERIALS AND METHODS}

Onlay preparation with three cusps coverage of upper $1^{\text {st }}$ molar was prepared on zirconium model (Fig. 1). Preparation was made with 2-3 $\mathrm{mm}$ of axial and occlusal reduction. A transparent template matrix of an ideally contoured upper $1^{\text {st }}$ molar crown was used to aid standardized onlay restorations construction.

Onlay restorations were fabricated according to the groups they belonged (Fig. 1):

Group A: (control group) made from plain particulate filler composite resin PFC (Z250, 3M-ESPE, USA).

Group B: made from short fiber-reinforced composite FC resin (everX posterior, Stick Teck Ltd, member of GC, Turku, Finland) as substructure with $1 \mathrm{~mm}$ surface layer of PFC

\section{Group C: made from FC composite resin.}

The onlay restorations of each group $(n=8)$ were polymerized with hand-light curing unit (Optilux 501, Kerr, CT, USA) for $80 \mathrm{~s}$ from all directions (wavelength: 380 and 520 $\mathrm{nm}$ with maximal intensity at $470 \mathrm{~nm}$, light irradiance 800 $\mathrm{mW} / \mathrm{cm} 2$ ). Subsequently after polymerization, the zirconium model with the onlay restoration was fixed to the metal base of testing device before statically loaded (spherical Ø $3 \& 6$ $\mathrm{mm}$ ) (Fig. 1). Luting cement was not used and the restorations were tightly fixed solely by resin. The static compressive fracture test was performed using a universal testing machine (model LRX, Lloyd Instruments Ltd., Fareham, $\mathrm{UK}$ ) at a speed of $1 \mathrm{~mm} / \mathrm{min}$, and data were recorded using PC software (Nexygen Lloyd Instruments Ltd.). The loading event was registered until restoration fracture. Failure patterns of each loaded restorations were visually analyzed.

Data of the fracture load values were statistically analyzed with SPSS version 13 (SPSS Inc., Chicago, IL, USA) using analysis of variance (ANOVA) followed by the 


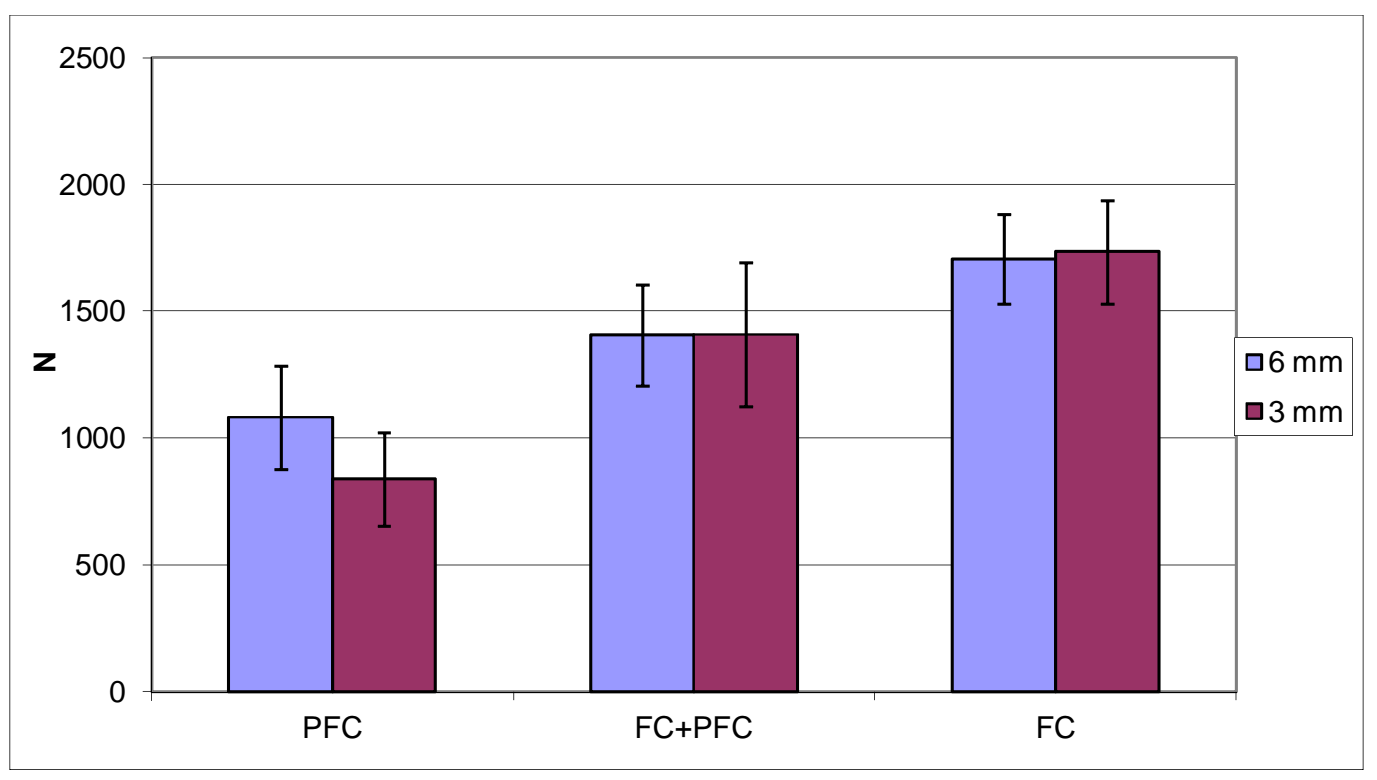

Fig. (2). Mean values of compressive load-bearing capacity of onlay restorations. N refers to Newton. PFC refers to particulate filler composite resin. FC refers to short fiber composite. FC+PFC refers to materials combination of FC substructure and covered with a $1 \mathrm{~mm}$ layer of PFC. Vertical lines represent standard deviations.

Tukey's post hoc test at a significance level of 0.05 to determine the differences between the groups.

\section{RESULTS}

The mean load-bearing capacities of the onlay restorations with standard deviations (SD) are given in Fig. (2). ANOVA revealed that onlay restorations made from short fiber FC composite resin had significantly higher loadbearing capacity $(1733 \mathrm{~N})(\mathrm{p}<0.05)$ than those made only from conventional particulate filler composite PFC (control) (1081 N).

Onlays made of FC composite resin with a surface layer of PFC gave force values of $1405 \mathrm{~N}$ which was statistically higher than control group $(p<0.05)$. No statistically significant difference was found in the load-bearing capacity between groups loaded by different ball sizes. Except with Group A (made from only PFC) had tendency to fracture more easily with smaller loading ball. Visual inspection revealed two types of fracture patterns according to the material used: catastrophic splitting of loaded cusps in restorations made of PFC composite resin, and chipping restoration fracture was found in all restorations made from either plain or substructure FC composite resin.

\section{DISCUSSION}

In our laboratory study we examined the fracture resistance of composite specimens simulating posterior an onlay restorations. After years of follow-up of indirectly or directly made posterior composite restorations, the clinical studies show that fracture of the restoration is the most common reason for failure, with no significant differences between the two techniques $[1,21,22]$. On the other hand, promising laboratory results were documented with the use of short fiber FC composite resin in high stress-bearing applications [16-20].
It was hypothesized that a $\mathrm{FC}$ composite resin substructure could reinforce the composite in onlay restoration for use in high stress-bearing areas of the dental arch. The data showed substantial improvements in load-bearing capacity when materials combination were used (Fig. 2). The function of bulk short fiber composite substructure is based on supporting the surface particulate filler composite layer and working as crack stopper layer. Reinforcing effect of the fiber fillers is based on stress transfer from polymer matrix to fibers but also behavior of individual fiber as a crack stopper. Random fiber orientation had a significant role in mechanical properties. Clinical study reported by Van Dijken have shown that restorative composite with microfibers suffer extensive wear [23], which can be partly explained because of the used fiber length was well below of critical fiber length. In order a fiber to act as an effective reinforcement for polymers, stress transfer from the polymer matrix to the fibers is essential $[24,25]$. This is achieved, if the fibers have a length equal or greater than the critical fiber length [24]. It has been measured using fiber fragmentation test that the critical fiber lengths of E-glass with bis-GMA polymer matrix vary between 0.5 and $1.6 \mathrm{~mm}$ [26]. Deteriorated or initially poor adhesion between the fibers and polymer matrix increase the critical fiber length. In this case, the mechanical friction of fibers to polymer matrix at the interface can compensate the poor adhesion [27]. Based on this, the short fiber composite resins used in this study have fiber fillers equal or greater to critical fiber length.

To receive support from the short fiber composite substructure for the surface particulate composite, the structural rigidity of the short fiber composite substructure should be higher than that of surface particulate composite resin. In this, the fiber orientation likely has a significant role. On the other hand, if the function of the short fiber composite substructure is based on the mechanism of a crack stopper, the distance from the surface of the stress initiation point to the 
fibers is of importance. Therefore, the volume fraction or thickness of short fiber composite could contribute to the crack propagation and load-bearing capacity. Previous study by authors, showed when short random fiber-reinforced composite (FRC) was used as substructure for particulate filler composite, the load-bearing capacity of the materials combination increased linearly as thickness layer of FRC increased $[1,28]$. From this point of view, in this experimental study, short fiber composite substructure was covered with only $1 \mathrm{~mm}$ layer thickness of hybrid particulate filler composite resin.

The alteration of ball size changes the position of load applications, modifying the concentration of tension patterns [29]. Habekost et al. showed that force required to cause fracture with $10 \mathrm{~mm}$ diameter ball was greater than with the $3 \mathrm{~mm}$ diameter ball [29]. However, contrary to expectation, in this study no statistically significant difference was found in the load-bearing capacity between groups loaded by $6 \mathrm{~mm}$ or $3 \mathrm{~mm}$ metal ball. This might be because of the small diameter's difference between balls was not mechanically influence.

Stress applied to the teeth and dental restorations is generally low and repetitive rather than being isolated and impactive in nature. However, because of a linear relationship between fatigue and static loading, the compressive static test also gives valuable information concerning load-bearing capacity [30].

The fracture resistance values determined by the various investigators were recorded under different measurement criteria. These criteria were either initial cracking that was interpreted as crack development or a reduction in the load by an absolute or relative amount [1,31,32]. For this study, the maximum force on the final fracture was determined. Fracture patterns were analyzed visually and two types of fracture patterns were found, where each fracture type occurred according to the type of material. Because of the brittleness of composite resin, the catastrophic splitting of cusps was found in all specimens made from PFC only. In contrast, short fiber composite allowed the crack to propagate through the surface PFC and FC composite resin to make a compound-like fracture with no delamination found.

Methodologically, limitations like sample size and aging process, such as alternate thermal stress, mechanical stress, wear and water storage, should be taken into consideration. Despite the importance of laboratory studies to answer some questions in a short time, the real performance of restorations can only be determined by long-term clinical trials.

\section{CONCLUSIONS}

Within limitations of this experimental study, the results showed good performance of a novel materials combination of bulk short fiber composite substructure and surface layer of particulate filler composite in high stress bearing areas.

\section{CONFLICT OF INTEREST}

The authors confirm that this article content has no conflicts of interest.

\section{ACKNOWLEDGEMENTS}

None declared.

\section{REFERENCES}

[1] Garoushi S, Lassila LVJ, Vallittu PK. Fiber-reinforced composite substructure: load bearing capacity of an onlay restoration. Acta Odontol Scand 2006; 64: 281-5.

[2] Dumfahrt H, Schaffer H. Porcelain laminate veneers. A retrospective evaluation after 10 years of service: Part II Clinical results. Int J Prosthodont 2000; 13: 9-18.

[3] Friedman MJ. A 15-year review of porcelain veneer failure: a clinician's observations. Compend Contin Educ Dent 1998;19: 625-32.

[4] Felden A, Schmalz G, Hiller KA. Retrospective clinical study and survival analysis on partial ceramic crowns: results up to 7 years. Clin Oral Investig 2000; 4: 199-205.

[5] Selz CF, Strub JR, Vach K, Guess PC. Long-term performance of posterior In Ceram Alumina crowns cemented with different luting agents: a prospective, randomized clinical split-mouth study over 5 years._Clin Oral Investig 2013 (Epub ahead of print)

[6] Gegauff AG, Garcia JL, Koelling KW, Seghi RR. Thermoplastic composites for veneering teeth: a feasibility study. Dent Mater 2002; 18: 479-85.

[7] Fennis WM, Kuijs RH, Roeters FJ, Creugers NH, Kreulen CM. Randomized control trial of composite cuspal restorations: fiveyear results. J Dent Res 2013. (Epub ahead of print)

[8] Ferracane JL, Berge HX, Condon JR. In vitro aging of dental composites in water effect of degree of conversion, filler volume, and filler/matrix coupling. J Biomed Mater Res 1998; 42: 465-72.

[9] $\mathrm{Xu} \mathrm{HH}$, Quinn JB, Smith DT, Giuseppetti AA, Eichmiller FC. Effect of different whiskers on the reinforcement of dental resin composites. Dent Mater 2003;19: 359-67.

[10] Burke FJ, Watts DC, Wilson NH, Wilson MA. Current status and rationale for composite inlays and onlays. Br Dent J 1991;170: 269-73.

[11] Wendt SL, Leinfelder KF. The clinical evaluation of heat-treated composite resin inlays. J Am Dent Assoc 1990; 120: 177-81.

[12] Loza-Herrero MA, Rueggeberg FA, Caughman WF, Schuster GS, Lefebvre CA, Gardner FM. Effect of heating delay on conversion and strength of a post-cured resin composite. J Dent Res 1998; 77: 426-31.

[13] Hejazi AAE, Watts DC. Creep and visco-elastic recovery of cured and secondary-cured composites and resin-modified glass ionomers. Dent Mater 1999; 15: 138-43.

[14] Zandinejad AA, Atai M, Pahlevan A. The effect of ceramic and porous fillers on the mechanical properties of experimental dental composites. Dent Mater 2006; 22: 382-7.

[15] Wilder Jr. AD, Bayne SC, Heymann HO. Long-term clinical performance of direct posterior composites. Trans Acad Dent Mater 1996; 9: 151-69.

[16] Xu HH. Dental composite resins containing silica-fusedceramic single-crystalline whiskers with various filler levels. J Dent Res 1999; 78: 1304-11.

[17] Garoushi S, Vallittu PK, Lassila LVJ. Short glass fiber reinforced restorative composite resin with semi-interpenetrating polymer network matrix. Dent Mater 2007; 23:1356-62.

[18] Garoushi S, Vallittu PK, Lassila LVJ. Direct restoration of severely damaged incisors using short fiber-reinforced composite resin. J Dent 2007; 35: 731-36.

[19] Garoushi S, Vallittu PK, Watts DC, Lassila LVJ. Polymerization shrinkage of experimental short glass fiber reinforced composite with semi-inter penetrating polymer network matrix. Dent Mater 2008; 24: 211-15.

[20] Garoushi S, Vallittu P, Lassila LVJ. Fracture toughness, compressive strength and load-bearing capacity of short glass fiberreinforced composite resin. Chin J Dent Res 2011; 14: 15-19.

[21] Garoushi S, Säilynoja E, Vallittu PK, Lassila L. Physical properties and depth of cure of a new short fiber reinforced composite. Dent Mater 2013; 29: 835-41.

[22] Pallesen U, Qvist V. Composite resin fillings and inlays: an 11-year evaluation. Clin Oral Invest 2003; 7: 71-9.

[23] Wassell RW, Walls AWG, McCabe JF. Direct composite inlays versus conventional composite restorations: 5-year follow-up. J Dent 2000; 28: 375-82. 
[24] Van Dijken JWV, Grönberg KS. Fiber-reinforced packable resin composite in class II cavities. J Dent 2006; 34: 763-9.

[25] Petersen RC. Discontinuous fiber-reinforced composites above critical length. J Dent Res 2005; 84: 365-70.

[26] Vallittu PK, Lassila VP, Lappalainen R. Transverse strength and fatigue of denture acrylic-glass fiber composite. Dent Mater 1994; 10: $116-21$.

[27] Cheng TH, Jones FR, Wang D. Effect of fiber conditioning on the interfacial shear strength of glass-fiber composite. Compos Sci Technol 1993; 48: 89-96.

[28] Karacaer Ö, Polat TN, Tezvergil A, Lassila LVJ, Vallittu PK. The effect of length and concentration of glass fibers on the mechanical properties of an injection- and a compression-molded denture base polymer. J Prosthet Dent 2003; 90: 385-93.
[29] Garoushi S, Lassila LVJ, Tezvergil A, Vallittu PK. Load bearing capacity of fiber-reinforced and particulate filler composite resin combination. J Dent 2006; 34: 179-84.

[30] Habeksot LV, Camacho GB, Pinto MB, Demarco FF. Fracture resistance of premolars restored with partial ceramic restorations and submitted to two different loading stresses. Oper Dent 2006; 31: 204-211.

[31] Garoushi S, Lassila LV, Tezvergil A, Vallittu PK. Static and fatigue compression test for particulate filler composite resin with fiber-reinforced composite substructure. Dent Mater 2007; 23: 1723.

[32] Stipho HD. Effect of glass fiber reinforcement on some mechanical properties of autopolymerizing polymethyl methacrylate. J Prosthet Dent 1998; 79: 580-4.

(C) Garoushi et al.; Licensee Bentham Open.

This is an open access article licensed under the terms of the Creative Commons Attribution Non-Commercial License (http://creativecommons.org/licenses/by-nc/3.0/) which permits unrestricted, non-commercial use, distribution and reproduction in any medium, provided the work is properly cited. 